\title{
Strategies to prevent the metabolic syndrome at the population level: role of authorities and non-governmental bodies
}

\author{
Åke Bruce \\ National Food Administration, PO Box 622, SE-751 26 Uppsala, Sweden
}

\begin{abstract}
The remarkable increase over the past 40 years in some chronic diseases, including the metabolic syndrome, has increased the demand for government and international policies to encourage various approaches to decrease the risk of these diseases. There are some prerequisites for working out successful national food and nutrition policies. Firstly, it is necessary to have a clear picture of the dietary pattern in a country and its associated public health problems. Based on these data, nutrient recommendations and goals are formulated by international or national scientific committees. Governments should translate these nutrient goals into food goals and eventually into national dietary guidelines. The means by which the national authorities can implement a nutrition policy include fortification and supplementation. Equally important are educational and informative tools, such as labelling on the packed food products including information about ingredients and nutrient content. With respect to the metabolic syndrome, this implies nutrient recommendations regarding the intake of fat and carbohydrates (energy per cent) and dietary fibre; dietary guidelines regarding balance between energy intake and expenditure; decreased consumption of products rich in fat and increased consumption of cereals and other products rich in dietary fibre, etc.; recommendations from the authorities regarding nutrient labelling (content of fat and dietary fibre) on relevant products; and nutrient and health claims and other aids (symbols) as tools to make it easier for consumers to select the appropriate food products.
\end{abstract}

Dietary guidelines: Labelling: Health claims

In an international context the nutritional status among large segments of the population in western countries is very good. As the socio-economic situation has improved, so has the health and nutrition situation. In most countries, life expectancy has never been as high as it is today. Access to food is no problem, nor are health problems due to energy or nutritional deficiencies. However, the high standard of living enjoyed by many Europeans in recent decades has also created new problems. The most prevalent diseases in western European middle-aged populations today are cancer and cardiovascular diseases, both of which are clearly linked to lifestyle (Swedish Ministry of Health and Social Affairs, 1993). The remarkable increase over the past 40 years in these and other chronic diseases, including the metabolic syndrome, has increased the demand for government and international policies to encourage a preventive as well as a therapeutic approach to these diseases. No policy on the prevention of a disease can be developed without a basic, realistic assessment of its prevalence and its impact on national morbidity and mortality.

The metabolic syndrome is characterized by an association of elevated insulin levels, a tendency to abdominal obesity, a disturbance of lipid metabolism with elevated triglyceride and low HDL levels, and commonly associated hypertension. Each of these has a dietary relation: obesity (balance between energy intake and energy expenditure, the energy density of the diet); hypertension (obesity, sodium intake); and dyslipidaemia (intake of fat and fatty acids). Foods rich in dietary fibre and foods with a low glycaemic index are also of importance.

\section{Public health policy}

The aim of the national health polices in most industrialized countries is to improve the health status of the population as a whole and to diminish the social differences in this respect. In the implementation of this policy, food and nutrition is only one of the areas where measures are taken, but an important one.

Public health is the responsibility of many different authorities and organizations. Preventive health care is largely provided at the local and regional levels. For the conditions forming the metabolic syndrome the most effective prevention is usually through secondary prevention 
measures at a local or regional level and directed towards the individual at risk. The possible role of the physicians in these matters was recently the topic of a symposium (Truswell 1999). Such programmes, either through the official health service or through various non-governmental organizations, should be supported and encouraged by the national health authorities.

The government agencies and ministries that are immediately concerned with dietary matters on a national level are those responsible for food and nutrition, health and welfare, but also those working with agriculture and consumers. Other authorities with responsibility for education, consumer policy, agricultural policy and environmental and chemical matters may also be concerned with public health in the broadest sense of the term.

There are some prerequisites for working out successful national food and nutrition strategies or policies. Firstly, it is necessary to have a clear picture of the dietary pattern in a country and its associated public health problems. These aspects are outside the scope of this paper, but the present Swedish situation has recently been presented (Becker 1999). Based on these data, national nutrient recommendations and goals are formulated by international or national scientific committees. Governments should translate these nutrient goals into food goals and eventually into dietary guidelines.

The formulation of a nutrition strategy is a complex task which demands an understanding of all the principal factors involved in the food chain. The means which could be used by the national authorities include fortification (addition of nutrients to food) and supplementation (recommendations regarding vitamin and mineral tablets). Equally important are educational and informative tools, such as labelling on the packed food products, including information about ingredients and nutrient content. In addition to this, nutrient and health claims could be accepted.

\section{Nutrition recommendations}

In public health nutrition there are two major sets of messages from the consensus of nutritional scientists to the population - recommended nutrient intakes and dietary guidelines. The former recommendations advise the quantities of essential nutrients that people ought to consume. Recommended nutrient intakes are authoritative, quantitative estimates based on human requirements for essential nutrients, considered to be adequate to meet the known nutritional needs of practically all healthy people.

Since 1977 the Nordic countries (Denmark, Finland, Iceland, Norway and Sweden) together have elaborated the Nordic Nutrition Recommendations, and the third edition was published in 1996 (Nordic Council of Ministers 1996), with a Swedish version in the following year. The recommendations are based on the present nutritional situation and aim at defining the basis for planning a diet that:

(1) satisfies the primary nutritional requirements, i.e. meets the physiological requirements of each individual for growth and function (nutrient recommendations); and

(2) provides the prerequisites for general good health and reduces the risk of diseases caused by faulty diets.

\section{The food circle}

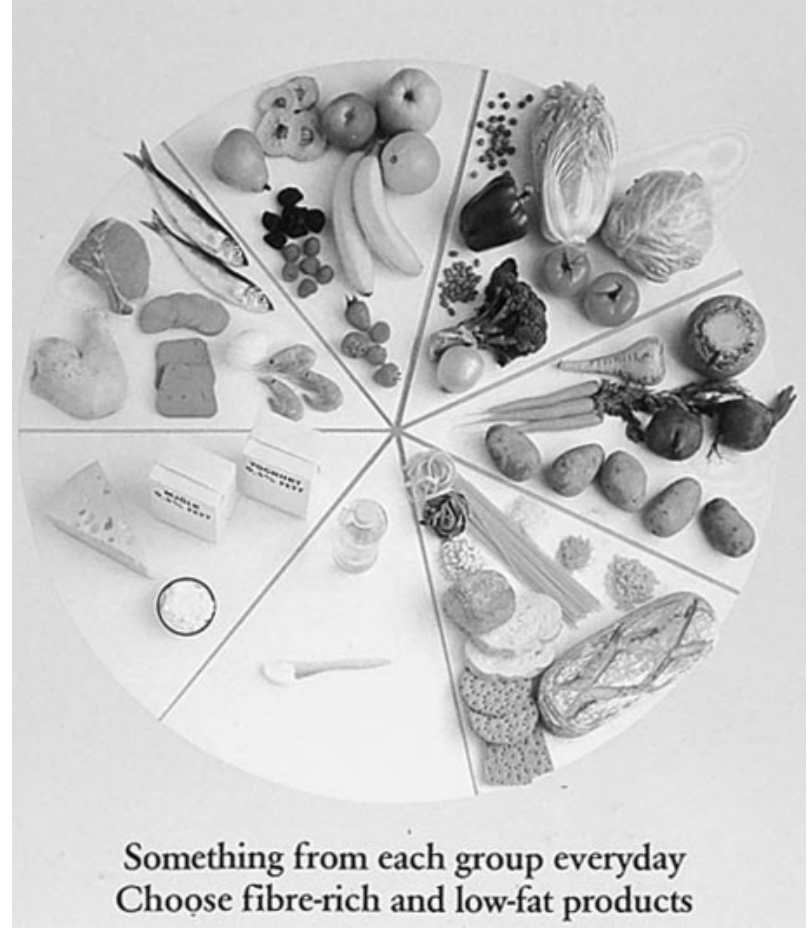

Fig. 1. The Swedish food circle.

A major part of the recommendations is for the planning of diets for adults and children above 3 years of age. Protein should provide $10-15 \%$ of the total energy intake and fat $\leqslant 30 \%$. The intake of polyunsaturated fatty acids should be 5-10 energy per cent including approximately one energy per cent of $n-3$ fatty acids. Carbohydrates should provide $55-60 \%$ of the energy intake, of which less than $10 \%$ of the energy should be provided by refined sugars in children and adults with low $(<8 \mathrm{MJ})$ energy intake.

The need for nutrients is most easily met if the diet is varied and for each day contains leafy vegetables, fruit, potatoes and root vegetables, dairy products, meat, fish or eggs, cereals, and edible fats (the Swedish 'food circle', Fig. 1). Recommendations for a suitable meal pattern are also given. Diets which comply with these recommendations and are varied and consumed in such a quantity that the individual's requirement for energy is met should as a rule provide a person with sufficient amounts of the individual nutrients.

These recommendations now serve as the basis for development of various dietary guidelines (for meals services for schools, children's day-care centres, hospitals, etc.), for food standards, and for health-directed campaigns at the national or regional level.

\section{Dietary guidelines}

In affluent countries, achievement of nutrient intakes near the recommended levels can be taken for granted by most 
people. Other sets of authoritative statements, called dietary guidelines, have emerged since the late 1960s; these guidelines advise consumers how to select from the many combinations of foods adequate diets to give the best chances of long-term health. They have been produced because it was realized that most of the nutritional problems and opportunities in affluent countries were not related to lack of essential nutrients, and that the recommended dietary allowances did not give enough information in practice.

In Sweden, a joint expert group for dietary and public health matters was formed around 1970. The primary task of this group was to draw up a scientific basis for information on diet and exercise. The first report of the group was published in 1971, and the latest edition appeared in 1992 (Socialstyrelsen och Statens Livsmedelsverk, 1992; Bruce, 1997). The reports describe the present dietary situation, its importance for public health, the principles for desirable changes in dietary habits and physical exercise, and how these principles could be carried out in practice, and provide the scientific background to the Swedish dietary guidelines. The present guidelines (third edition) are presented as follows (Socialstyrelsen och Statens Livsmedelsverk, 1992):

- low intensive physical activity ought to be undertaken regularly, preferably daily

- avoid overweight by adapting energy intake to the expenditure of energy; for most people this means increased daily physical activities and reduced energy intake

- intake of fat should not exceed $30 \%$ of energy intake; for most people this means a decrease in fat consumption, and such a decrease ought to occur primarily through a decreased consumption of saturated fatty acids to not more than $10 \%$ of energy

- intake of dietary fibre should increase to $3 \mathrm{~g} / \mathrm{MJ}$ per d, which corresponds to $25-30 \mathrm{~g} / \mathrm{d}$

- intake of refined sugars should be $10 \%$ of the energy intake or less, especially for low-energy users

- intake of salt should gradually decrease to 5-6 g/d

- alcohol consumption ought to be moderate or entirely avoided

- consumption of foods rich in starch should increase; most Swedes should eat more bread and other grain products, pasta, rice, potatoes and root vegetables

- food from all seven food groups (Fig. 1) ought to be consumed every day

- avoid prolonged frying of meat and fish

- daily intake of energy ought to be divided into three main meals and two or more snacks

- each meal should include several vegetables, root vegetables, fruit and/or berries

Information regarding present dietary guidelines in a number of other countries was recently published by Truswell (1998).

\section{Implementing dietary guidelines}

\section{The seven food group system, the Swedish food circle}

Over the years several different ways have been used of teaching nutrition to the general public. The method of dividing foods into food-group systems has been used since the beginning of the 20th century, and the present Swedish version was elaborated during the 1950s. As seen in Fig. 1, it comprises seven food groups: vegetables, fruit and berries; potatoes and root vegetables; bread, flour and grains; edible fats; milk and cheese; meat, fish and eggs. The recommendation is that foods from each group in the food circle should be consumed every day. Today these seven food groups are also included in the Swedish nutrition recommendations.

\section{The plate model}

Among health professionals who provide dietary advice there has long been a need for a simple education tool for use when advising individuals what to eat. The need for a simpler method to teach proper daily nutrition has led to the development of a plate model (Fig. 2). It is easy to use in teaching and appears to be easy to memorize. The plate is divided into three sections, by an inverted $\mathrm{Y}$. The smallest part, at most one-quarter of the surface, represents the dietary contribution from meat, cheese, fish and eggs. The other two sections are of equal size and represent the dietary contribution of (i) vegetables and fruit, and (ii) rice, pasta, potatoes and bread. It should be noted that the plate model describes the proportions of different foods in a meal and not only what is actually on the plate. This means that in a lunch or dinner meal, bread and fruit should be included to fulfil the dietary recommendations. In the case of a meal such as soup, stew or pizza, for example, it is obviously difficult to divide the plate into the three sections, but the whole meal should still be considered using the plate model approach. During recent years the plate model has become widely accepted and applied in dietary guidance. The message appears to

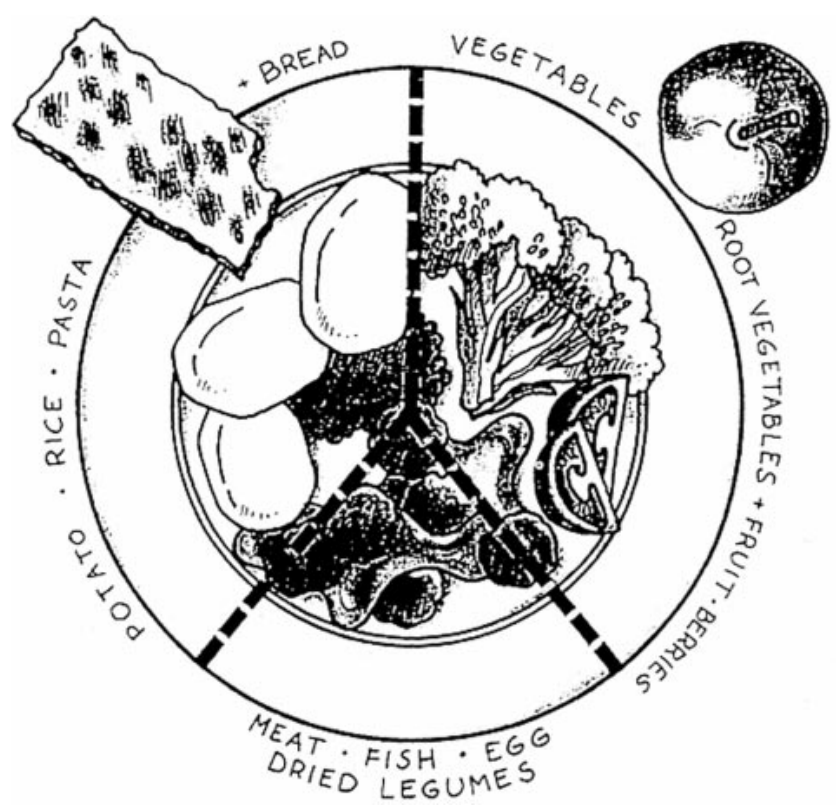

Fig. 2. The Swedish plate model. 
be easy to understand, memorize and use in daily life (Nydahl et al. 1993).

\section{Labelling and claims}

Ingredient labelling, i.e. the declaration of all ingredients in descending order of predominance, has been required on most packed food products for over 40 years. The only exceptions are certain standardized foods. Hence for most products consumers can work out what is actually in the foods they purchase. A major medical reason for such ingredient listings is to make it possible to avoid ingredients to which individuals may be allergic.

In addition, there is generally a nutrition label stating the content of relevant nutrients in the products. In several countries these figures are related to a standard and expressed as a percentage of recommended intake.

\section{Symbol labelling}

In 1989 the Swedish National Food Administration decided that a number of foodstuffs which either had a low fat content or were rich in dietary fibre could be labelled with a special symbol (a key-hole in a green or black circle, Fig. 3.) The purpose of this was to make it easier for consumers when shopping to choose foodstuffs that are desirable from a nutritional point of view and to encourage the food producers to broaden the supply of low-fat or fibre-rich products.

The key-hole symbol can be printed on the packaging of accepted products, attached on the shelves in shops, or used in advertising or marketing of the products. The symbol is free to use and no previous acceptance or licensing is necessary. Its application is supervised by the local public health administration. However, the products must meet the standards set up by the National Food Administration and the symbol must be printed in green or black.

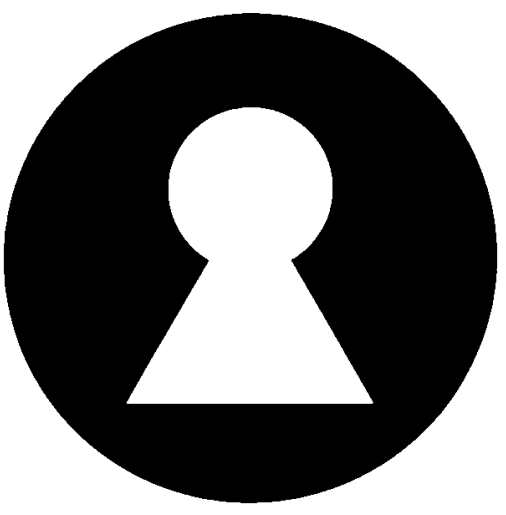

Fig. 3. The key-hole symbol used in Sweden since 1989.

The principle of symbol labelling is to label foodstuffs that are considered to be a better choice concerning the content of fat and dietary fibre, in groups of foodstuffs where there are products with a high as well as low content of fat or dietary fibre. Groups of foodstuffs that include only products that are low in fat or rich in dietary fibre (for instance vegetables and fruit) are not labelled.

Today the key-hole symbol has become a simple aid to purchasing healthy food. An increasing percentage of consumers know what the key-hole means, and they are guided by the symbol when buying food. The symbol is now found on almost all products that qualify for it. The present conditions for symbol labelling are presented in Table 1. A recent study by Larsson et al (1999) showed that in a group of more than 1600 middle-aged men and women in Göteborg, those with knowledge of the symbol seemed to have adopted the low-fat message. However, in certain subgroups, particularly the less well-educated, awareness of the symbol appeared to have no association with dietary practices.

Table 1. The present conditions for symbol labelling in Sweden

\begin{tabular}{|c|c|c|}
\hline Food & $\begin{array}{l}\text { Fat content } \\
(\mathrm{g} \text { per } 100 \mathrm{~g})\end{array}$ & Other \\
\hline Milk & $\leqslant 0.5$ & \\
\hline 'Natural' fermented milk & $\leqslant 1.5$ & Sugar should not have been added \\
\hline Fermented milk with added sugar and/or jam etc. & $\leqslant 0.5$ & \\
\hline Skimmed milk powder & $\leqslant 1.5$ & \\
\hline Cottage cheese & $\leqslant 4$ & \\
\hline Processed cheese and whey products & $\leqslant 10$ & \\
\hline Other types of cheese & $\leqslant 17$ & \\
\hline Margarine, minarine and similar fats & $\leqslant 41$ & \\
\hline Ice creams & $\leqslant 6$ & \\
\hline Unmixed (whole) meat products and minced meat & $\leqslant 10$ & \\
\hline Mixed meat products, including sausages & $\leqslant 15$ & \\
\hline Bread, biscuits, rusks, pasta products and breakfast cereals & & $\begin{array}{l}\text { At least half of the cereal components should be wholemeal } \\
\text { flour or the product should contain at least } 7 \% \text { dietary fibre } \\
\text { (dry weight basis) }\end{array}$ \\
\hline Flour, cereals and grains & & $\begin{array}{l}\text { Product should be based on wholemeal grain or contain at } \\
\text { least } 11 \% \text { dietary fibre (dry weight basis) }\end{array}$ \\
\hline Breakfast cereals & & $\begin{array}{l}\text { Product should contain at least two-thirds wholemeal grain } \\
\text { or at least } 9 \% \text { dietary fibre (dry weight) and contain less } \\
\text { than } 13 \% \text { sugar }\end{array}$ \\
\hline $\begin{array}{l}\text { 'Ready-to-eat' foods; entire meals; restaurant dishes based } \\
\text { on meat, fish or vegetables and with potato, rice or pasta }\end{array}$ & $\begin{array}{l}\leqslant 30 \% \text { of } \\
\text { energy }\end{array}$ & \\
\hline
\end{tabular}


Table 2. Health claims are allowed in Sweden for the following conditions (Swedish Nutrition Foundation, 1996)

\begin{tabular}{ll}
\hline Condition & Basis for claims \\
\hline Obesity & $\begin{array}{l}\text { Obesity or overweight can be prevented through a diet which has a low or reduced energy content. Energy } \\
\text { reduction through lower amounts of fat is especially important }\end{array}$ \\
Cholesterol level in the blood & $\begin{array}{l}\text { Reduction in saturated fat intake, by lowering total fat or by replacing saturated fat by mono-unsaturated or } \\
\text { polyunsaturated fat, may help to reduce the blood cholesterol level. As trans-fatty acids also increase the level of } \\
\text { cholesterol in the blood, health claims should not be made for products with a high level of trans-fatty acids. Some } \\
\text { types of soluble, gel-forming dietary fibre can contribute to a reduction in cholesterol level }\end{array}$ \\
A reduction in salt (sodium chloride) consumption can counteract high blood pressure. The use of mineral salts \\
containing potassium can contribute to a reduction in sodium intake, but there is no other documented positive \\
effect of mineral salts on blood pressure
\end{tabular}

\section{Health claims}

A health claim characterizes the relationship between a food, a nutrient, or another substance in a food, and the risk of a health-related disease or condition. There is great public interest in matters relating to health and food, and as a result it has become increasingly common to use health arguments in the labelling and marketing of food products. In recognition of the need to avoid misleading or false information when using health claims for the purpose of marketing food products, the Swedish food industry has prepared a programme of action in consultation and agreement with the National Food Administration and the National Board for Consumer Policies (Swedish Nutrition Foundation 1996; Bruce, 1997; Asp \& Laser Reuterswärd, 1999). The programme includes a number of generally accepted principles regarding the use of health claims in the labelling and marketing of food products. The health claims used must be limited to generally recognized and well documented causal connections between food and health. The claims must consist of two parts: information on a specific diet-health relationship, followed by information on the composition of the product - a two step principle. Claims and arguments about effects on physiological conditions and specific diseases must conform to official recommendations. Such claims must fulfil the requirement that normal use of the product contributes to a substantially improved diet from a nutritional point of view.

Marketing and information material containing health claims should promote consumer awareness of the connection between food and health. The claims should be presented in such a way as to enhance public confidence in food products and the food industry. These rules are applicable to all use of health claims in the marketing of food products, for example package labelling, advertising, product leaflets, recipes, information brochures and video, film and television commercials.
Since it is not possible to outline in detail and in advance all the issues that may arise in connection with the use of health claims in the labelling and marketing of food products, and as the relevant research is constantly making new advances, the agreement will be revised when required. An expert on nutritional matters at the Swedish Nutrition Foundation is available to food manufacturers to offer advice and comments on the factual content of health claims.

Since 1990 health claims and arguments have been allowed in Sweden for a number of conditions (Table 2). For each of these conditions there are special requirements regarding acceptable statements, based on the two-step principle described above.

\section{References}

Asp N-G \& Laser Reuterswärd A (1999) Health claims: the Swedish approach. In Forum on Functional Food, pp. 239262. Strasbourg: Council of Europe Publishing.

Becker W (1999) Dietary guidelines and patterns of food and nutrient intake in Sweden. British Journal of Nutrition 81 (Suppl. 2), S113-S117.

Bruce A (1997) Implementing dietary guidelines: Sweden. In Implementing Dietary Guidelines for Healthy Eating, pp. 245262 [V Wheelock, editor]. London: Chapman \& Hall.

Larsson I, Lissner L \& Wilhelmsen L (1999) The 'Green Keyhole" revisited: nutritional knowledge may influence food selection. European Journal of Clinical Nutrition 52, 1-5.

Nordic Council of Ministers (1996) Nordic Nutrition Recommendations 1996. Scandinavian Journal of Nutrition 40, 161165.

Nydahl M, Gustafsson I-B, Eliasson M \& Karlström B (1993) A study of attitudes and use of the plate model among various health professionals giving dietary advice to diabetic patients. Journal of Human Nutrition and Dietetics 6, 163-170.

Socialstyrelsen och Statens Livsmedelsverk (1992) Kost, Motion \& Hälsa. Stockholm: Allmänna förlaget. 
Swedish Ministry of Health and Social Affairs (1993) Sweden's Country Paper to the FAO/WHO International Conference on Nutrition 1992. Uppsala: National Food Administration.

Swedish Nutrition Foundation 1996. Health claims in the labelling and marketing of food products. In: The Food Industry's Rules (Self-Regulating Programme), p. 11. Lund, Sweden: SNF.
Truswell AS (1998) Practical and realistic approaches to healthier diet modifications. American Journal of Clinical Nutrition 67 (Suppl. 3), 583S-590S.

Truswell AS (ed.) (1999) International workshop: 'Family doctors and patients - is effective nutrition interaction possible?' European Journal of Clinical Nutrition 53 (Suppl. 2). 